\title{
Results of Gravity Observations Using a Superconducting Gravimeter at the Tibetan Plateau
}

\author{
Heping Sun, Jianqiao Xu *, Xiaodong Chen, Jiancun Zhou, and Xiange Lei \\ State Key Laboratory of Geodesy and Earth's dynamics, Institute of Geodesy and Geophysics, \\ Chinese Academy of Sciences, Wuhan, China
}

Received 13 February 2012, accepted 25 October 2012

\begin{abstract}
The tidal and nontidal gravity change characteristics in the Tibetan Plateau region were investigated using the continuous gravity measurements recorded with a superconducting gravimeter (SG) installed in Lhasa from December 8, 2009 to September 30, 2011. The results indicated that the precision of the tidal gravity observations with the SG in Lhasa was very high. The standard deviation of the harmonic analysis for the gravity tides was $0.498 \mathrm{~nm} \mathrm{~s}^{-2}$, and the uncertainties of amplitude factors in the four main tidal waves (i.e., $\mathrm{O}_{1}, \mathrm{~K}_{1}, \mathrm{M}_{2}$ and $\mathrm{S}_{2}$ ) were better than $0.002 \%$. In addition, the diurnal gravity tide observations clearly revealed a pattern of nearly diurnal resonance. As a result, it is affirmed that the station should act as a local tidal gravity reference in the Tibetan Plateau and its adjacent regions. The load effects of oceanic tides are so weak that the resulting perturbation in the gravimetric factors is less than $0.6 \%$. However, the load effects of the local atmosphere on either the tidal or the nontidal gravity observations are significant, although no seasonal variations have been found. After removing the atmospheric effects, the standard deviation of the harmonic analysis for the gravity tides decreased obviously from 4.160 to $0.498 \mathrm{~nm} \mathrm{~s}^{-2}$. Having removed the load effects of oceanic tides and local atmosphere, it is found that the tidal gravity observations are significantly different from those expected theoretically, which may be related to active tectonic movement and extremely thick crust in the Tibetan Plateau region. In addition, the Earth's free oscillations excited by 2011 Tohoku-Oki $\mathrm{M}_{\mathrm{w}}$ 9.0 Earthquake were successfully detected.
\end{abstract}

Key words: Tibetan Plateau, Lhasa, Gravimetric parameters, Loading effects, Earth's free oscillations

Citation: Sun, H., J. Xu, X. Chen, J. Zhou, and X. Lei, 2013: Results of gravity observations using a superconducting gravimeter at the Tibetan Plateau. Terr. Atmos. Ocean. Sci., 24, 541-550, doi: 10.3319/TAO.2012.10.25.02(TibXS)

\section{INTRODUCTION}

Ground-based continuous gravity measurements are a combined reflection of the transportation and exchanges of material and the deformation of the Earth, which are related to all kinds of environmental perturbations and geodynamic processes. The superconducting gravimeter (SG) has the advatages of high stability and sensitivity, and extremely low noise and drift. Its precision is as high as $0.5 \mathrm{~nm} \mathrm{~s}^{-2}\left(1 \mathrm{~nm} \mathrm{~s}^{-2}\right.$ is about one part of $10^{10}$ of the mean gravity acceleration on the Earth's surface). It is now the best instrument to survey the temporal gravity variations in the world. It has the potential to detect almost all signatures with periods ranging from serveral seconds related to coseimic movements to several

\footnotetext{
* Corresponding author

E-mail:xujq@asch.whigg.ac.cn
}

years related to the variations in the Earth's rotation, even the phenomena associated with the secular tectonic movements of local crust, such as the the Earth's free oscillations (Banka and Crossley 1999; Van Camp 1999; Lei et al. 2005; Park et al. 2005), the Earth's tides (Sun et al. 2001; Xu et al. 2004a), the load effects of barometric pressure (Sun and Lou 1998), the nearly diurnal resonance (Defraigne et al. 1994; Xu et al. 2002), translational oscilations of the solid inner core (Smylie 1992; Courtier et al. 2000; Rosat et al. 2003; Xu et al. 2010), Polar motion (Loyer et al. 1999; Xu et al. 2004b), secular crust deformation due to earthquakes or other reasons (Crossley et al. 2004; Imanishi et al. 2004; Richter et al. 2004; Xu et al. 2008) and so on. As a result, a significant scientific project, i.e., the Global Geodynamics Project, has been carried out since 1997 in order to investigate global and local dynamic problems using continuous 
gravity data from a worldwide network of superconducting gravimeters (Crossley et al. 1999; Crossley 2004; Crossley and Hinderer 2009). This project has produced numerous scientific achievements and benefited many disciplines.

The Tibetan Plateau is located on the collision region of the Indian and Eurasian Plates. It is the youngest orogen, and is the largest and highest plateau in the world. It is referred to as the Earth's third pole. Since the early $20^{\text {th }}$ century, many geodetic strategies, including trigonometrical surveys, arc measurements, leveling surveys, GPS measurements and gravity measurements, have been carried out by numerous international research institutes in order to gain knowledge of the present-day crustal deformation and movement status. The geodetic measurements have resulted in abundant information and basic data for studies on the mechanisms of the tectonic deformation in the plateau and led to some significant results (Ma et al. 2001; Wang et al. 2001, 2004; Xu 2001; Zhang et al. 2002; Sun et al. 2009). Lhasa is located on the southern part of the Tibetan Plateau, on the northern side of the Himalayan Mountains and on flat land in a valley in the middle reaches of the Lhasa River, a tributary of the Brahmaputra. A permanent station of continuous gravity measurements was set up in Lhasa by the Institute of Geodesy and Geophysics, Chinese Academy of Sciences at the end of 2009 in order to investigate the related geodynamical hotspots such as Tibetan Plateau's formation, evolution, uplifting rate and the related dynamic mechanism. An SG, coded as C057 was installed at the Lhasa station to monitor the continuous local gravity variations. Figure 1 shows the location of the Lhasa station and the tectonic environment and surrounding region. The characteris- tics of the tidal gravity changes in Lhasa were investigated using continuous gravity measurements over more than one year recorded with the SG (Xu et al. 2012).

The main motivation of this study is to investigate the tidal and non-tidal gravity changes, including accurate determinations of the gravimetric parameters, the load effects of oceanic tides and local atmosphere in the Tibetan Plateau, the Earth's free oscillations, and the nearly diurnal resonance in the diurnal tidal gravity observations.

\section{INSTALLATION AND PREPARATION}

The geographical coordinates of the Lhasa station are $29^{\circ} .645$ for latitude and $91^{\circ} .035$ for longitude, its altitude is $3632.3 \mathrm{~m}$. The station includes the $\mathrm{SG}$ measurement room, the SG monitoring room and a room for the contrast gravity measurements, shown in Fig. 2. Two square observation piers with side lengths of $1.2 \mathrm{~m}$ were built in the inter-comparison measurement room for convenient contrast observations of a relative or absolute gravimeter with the SG. The SG was installed on an equilateral triangle pier with side lengths of $77 \mathrm{~cm}$. All of the observation piers were concreted to a depth of $1 \mathrm{~m}$, fixed to a $30 \mathrm{~cm}$-thick bedding base and separated from the surroundings with a $10 \mathrm{~cm}$ wide slot to avoid perturbation from environmental noise, as shown in Fig. 3. A computer equipped in the monitoring room connects the SG through a cable and controls the SG and its related accessories by setting the associated parameters via the control system. The working status of the instrument can be monitored through a real-time display of pictures and related parameters. The data, including the gravity, baromet-

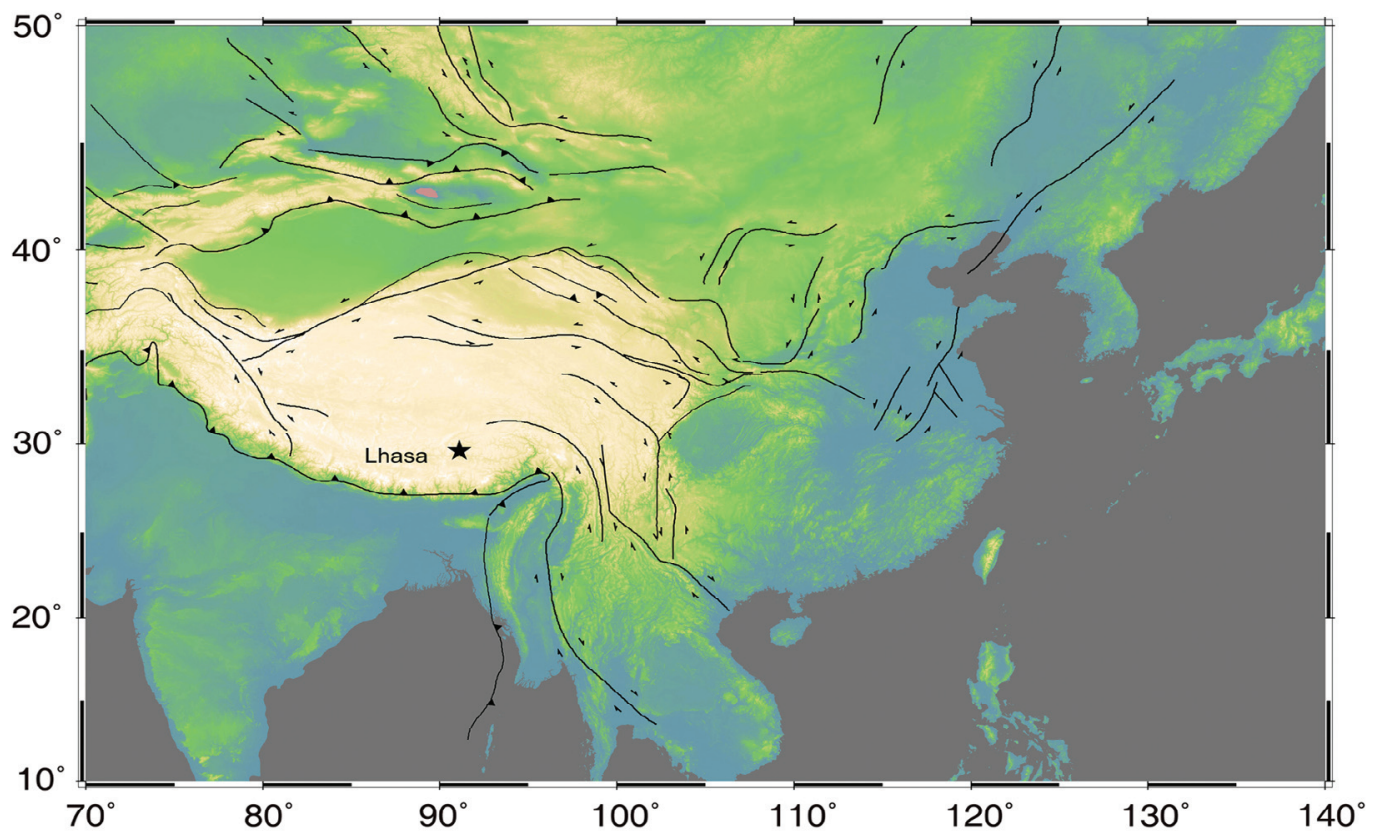

Fig. 1. Location of Lhasa Gravity Station. 


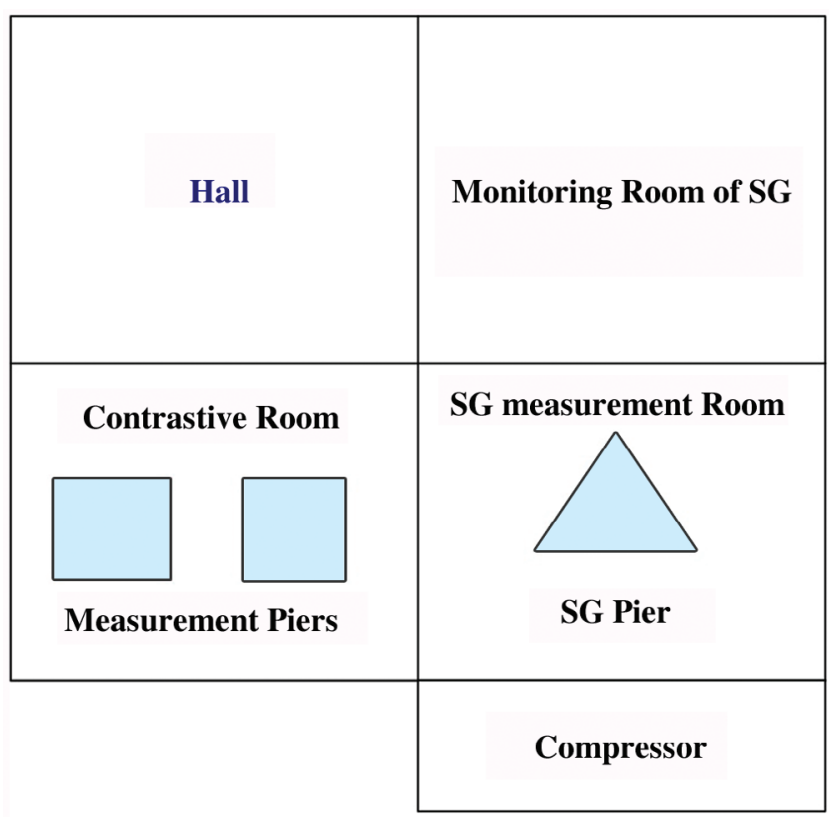

Fig. 2. Layout of Lhasa gravity station.

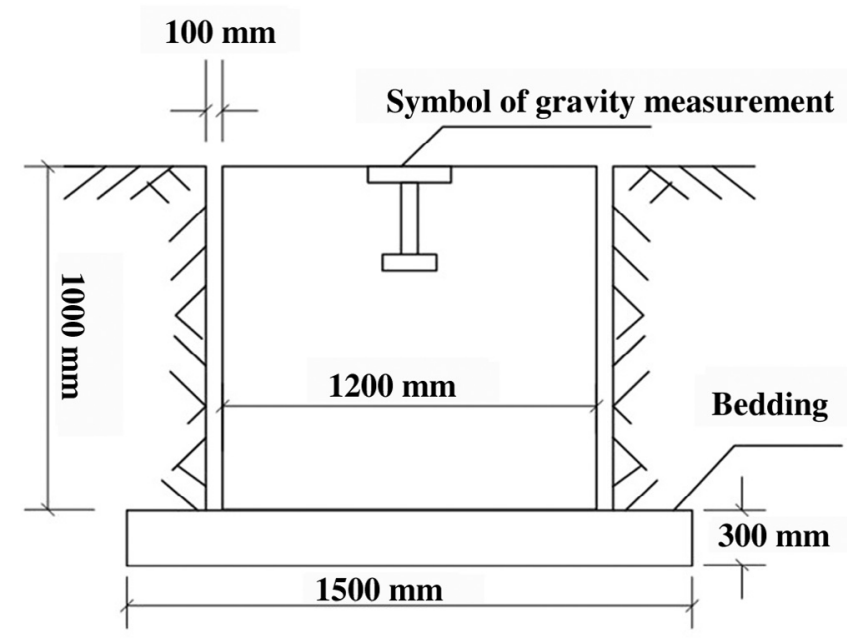

Fig. 3. Vertical section of the measurement pier.

ric pressure and temperature data are adopted automatically and stored by the computer. The control system also allows remote monitoring, control and data transfer to Wuhan via the Internet.

Like a spring gravimeter, the SG is also a relative gravimeter, and must be calibrated accurately. In order to determine accurately the SG scale factor, as well as normalize the tidal gravity observations to the international tidal gravity reference at Wuhan (Xu et al. 2000), a high-precision spring gravimeter, LaCoste-Romberg (LCR) ET20, was installed simultaneously in the contrast gravity measurement room to carry out parallel observations with the SG because it had worked perfectly at the Wuhan station for a long time. Af- ter primary preprocessing and harmonic analysis of the data recorded simultaneously with SG-C057 and LCR-ET20, the gravimetric amplitude factors of the main tidal waves were estimated. Using the observed amplitude factors of tidal waves $\mathrm{O}_{1}, \mathrm{~K}_{1}$ and $\mathrm{M}_{2}$ from the two gravimeters, the scale factor of SG-C057 was accurately determined as $-777.358 \pm$ $0.409 \mathrm{~nm} \mathrm{~s}^{-2} \mathrm{~V}^{-1}$ which is about $2.2 \%$ less than the value provided by the manufacturer (i.e., $-795 \mathrm{~nm} \mathrm{~s}^{-2} \mathrm{~V}^{-1}$ ). The relative precision of calibration was as high as $0.05 \%$, which completely satisfied the requirements for high-precision continuous gravity measurements (See Chen et al. 2012 and $\mathrm{Xu}$ et al. 2012 for details).

Software package T-Soft (Vauterin 1998), recommended by the International Center of the Earth's Tides for the analysis of Earth tide data, was employed to preprocess the gravity data. Using an interactive remove-restore technique, disturbances such as spikes, steps, off-sets, vibrations due to strong earthquakes and so on, were graphically removed and then corrected. Some short-time gaps due to happenstances such as sudden interruption of the electricity supply and instrument failure were interpolated in polynomials or spline functions. A 1s-sampled data series was transformed into a $1 \mathrm{~h}$-sampled one using a low-pass digital filter and presented in Fig. 4a.

\section{TIDAL GRAVITY OBSERVATIONS}

The SG is regarded as the best technique to investigate the nature of local tidal and nontidal gravity changes. Eterna3.30, a standard harmonic analysis software package (Wenzel 1996), was used. The gravimetric parameters (i.e., amplitude factor $\delta$ and phase difference $\Delta \varphi$ ) were accurately determined and tabulated in Table 1 . In harmonic analysis, a high-precision tide-generating potential, HW95, developed by Hartmann and Wenzel (Hartmann and Wenzel 1995) was used. The analysis results indicated that tidal gravity observation precision is very high. The standard deviation of the harmonic analysis was as little as $0.498 \mathrm{~nm} \mathrm{~s}^{-2}$, the gravimetric parameters $(\delta, \Delta \varphi)$ of the four main tidal waves were accurately estimated as $(1.16760 \pm 0.00006$, $\left.-0^{\circ} .0173 \pm 0^{\circ} .0028\right)$ for $\mathrm{O}_{1},\left(1.14166 \pm 0.00005,0^{\circ} .0636 \pm\right.$ $\left.0^{\circ} .0022\right)$ for $K_{1},\left(1.16940 \pm 0.00003,-0^{\circ} .4630 \pm 0^{\circ} .0012\right)$ for $\mathrm{M}_{2}$ and (1.16374 $\left.\pm 0.00006,-0^{\circ} .6606 \pm 0^{\circ} .0044\right)$ for $\mathrm{S}_{2}$, where the estimation precision of the amplitude factors was better than $0.006 \%$. For all the other tidal waves with amplitudes exceeding $20 \mathrm{~nm} \mathrm{~s}^{-2}$, it was better than $0.05 \%$ also. It implies that the tidal gravity observations from the $\mathrm{SG}$ were so accurate that they can be regarded as a regional tidal gravity reference in the Tibetan Plateau and its surrounding regions.

The dominant component in the observed residuals of the gravity tides arises mainly from the global and local oceanic tide load (OTL) effects in most areas of the world. Based on the classical theory of the Earth's surface loads 
(Farrell 1972) and available oceanic tide models, the load vectors $\boldsymbol{L}(L, \lambda)$ of all of these tidal waves were calculated using integrated Green's functions (Agnew 1997), which can be written as

$$
\boldsymbol{L}\left(\theta_{0}, \phi_{0}\right)=\rho_{0} \iint_{S} G(\psi) \boldsymbol{H}(\theta, \phi) d s
$$

where $\left(\theta_{0}, \phi_{0}\right)$ and $(\theta, \phi)$ are the colatitude and longitude of the station and integration element, respectively, $\boldsymbol{H}=H e^{-i \varphi}$ is the vector of the oceanic tide (including the height $\mathrm{H}$ and phase $\varphi$ ) provided in the oceanic tide models, $\psi$ is the angular distance from the station to the integration element and $G(\psi)$ is Green's functions for gravity changes excited by surface loads, which can be expressed as a linear combination of the load Love numbers.

In this study the recent global model of oceanic tides, FES04, deduced from the Topex/Poseidon altimeter data (Lefevre et al. 2002) was used. The model contains the cotidal maps of four diurnal and four semidiurnal tidal waves (i.e., $\mathrm{Q}_{1}, \mathrm{O}_{1}, \mathrm{P}_{1}, \mathrm{~K}_{1}, \mathrm{~N}_{2}, \mathrm{M}_{2}, \mathrm{~S}_{2}$ and $\mathrm{K}_{2}$ ) with a spatial resolution of $0.125^{\circ} \times 0.125^{\circ}$. The loading vectors were obtained and presented in Table 2 . The numerical results indicate that the tidal gravity observations were only slightly influenced by the OTL because Lhasa is located on the inland plateau far away from the oceans. Among all tidal waves, it is $\mathbf{M}_{2}$ whose amplitude of the OTL vector is the largest, which is $4.205 \mathrm{~nm} \mathrm{~s}^{-2}$, but only about $0.6 \%$ of its observed amplitude in gravity tides.

In order to clarify the OTL effects on the tidal gravity observations, an accurate theoretical model of the Earth's tides, where the inelasticity of the media in the mantle, mantle convection and excited deformation of the mantle boundaries were taken into account (Dehant et al. 1999), was used as a reference and denoted as DDW99. The observed residual vector $\boldsymbol{B}(B, \beta)$ was obtained through subtracting the theoretical vector from the observed vector for each tidal wave, and the difference of the observed residual vector $\boldsymbol{B}$ and the OTL vector $\boldsymbol{L}$ is defined as the final residual vector $\boldsymbol{X}(X, \chi)$. The relationship of these vectors is illustrated in Fig. 5. All of the related results of the OTL effects on the tidal gravity observations made with the SG are tabulated in Table 2. After removing the OTL effects, the amplitudes of the final residual vectors $\boldsymbol{X}$ of all tidal

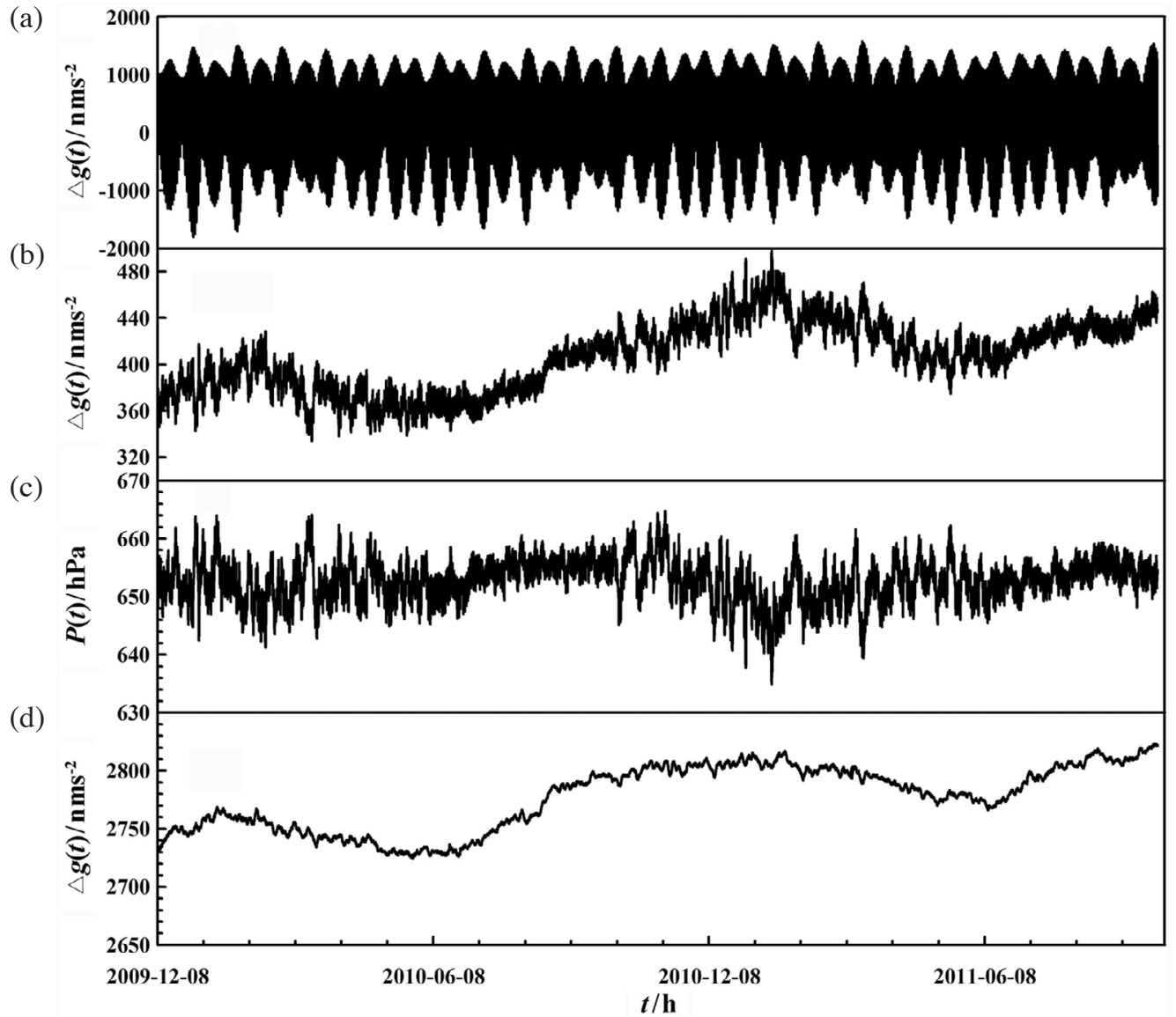

Fig. 4. Tidal and nontidal gravity changes observed with the SG at the Lhasa station from December 8, 2009 to September 30, 2011 . (a) 1h-sampled gravity changes, (b) the gravity residuals deduced by subtracting the tidal signatures from the original ones presented in (a), (c) the barometric pressure changes, and (d) the gravity residuals after removal the atmospheric effects. 
Table 1. Tidal gravity observations with the SG at Lhasa station from December 8, 2009 to September 30, 2011.

\begin{tabular}{|c|c|c|c|c|c|c|c|}
\hline \multirow{2}{*}{ Waves } & \multicolumn{2}{|c|}{ Frequency range (cpd) } & \multirow{2}{*}{$\begin{array}{c}\text { Theoretical } \\
\text { amplitude } \\
\left(\mathrm{nm} \mathrm{s}^{-2}\right)\end{array}$} & \multicolumn{4}{|c|}{ Observations with SG-C057 } \\
\hline & From & To & & $\delta$ & $\sigma(\delta)$ & $\Delta \varphi /\left(^{\circ}\right)$ & $\sigma(\Delta \varphi) /\left(^{\circ}\right)$ \\
\hline $\mathrm{SGQ}_{1}$ & 0.721499 & 0.833113 & 1.9721 & 1.15805 & 0.00619 & 0.6197 & 0.3060 \\
\hline $2 \mathrm{Q}_{1}$ & 0.851181 & 0.859691 & 6.7640 & 1.16573 & 0.00202 & 0.6845 & 0.0991 \\
\hline$\sigma_{1}$ & 0.860895 & 0.870024 & 8.1634 & 1.16924 & 0.00170 & 0.4258 & 0.0831 \\
\hline $\mathrm{Q}_{1}$ & 0.887326 & 0.896130 & 51.1178 & 1.17128 & 0.00028 & 0.2541 & 0.0138 \\
\hline$\rho_{1}$ & 0.897806 & 0.906316 & 9.7096 & 1.17367 & 0.00155 & 0.4065 & 0.0758 \\
\hline $\mathrm{O}_{1}$ & 0.921940 & 0.930450 & 266.9857 & 1.16760 & 0.00006 & -0.0173 & 0.0028 \\
\hline$\tau_{1}$ & 0.931963 & 0.940488 & 3.4822 & 1.15550 & 0.00422 & 0.1517 & 0.2092 \\
\hline $\mathrm{NO}_{1}$ & 0.958085 & 0.966757 & 20.9974 & 1.16233 & 0.00056 & -0.1111 & 0.0275 \\
\hline$\chi_{1}$ & 0.968564 & 0.974189 & 4.0158 & 1.16199 & 0.00390 & -0.2879 & 0.1923 \\
\hline$\pi_{1}$ & 0.989048 & 0.995144 & 7.2651 & 1.14898 & 0.00228 & -0.9279 & 0.1133 \\
\hline $\mathrm{P}_{1}$ & 0.996967 & 0.998029 & 124.2278 & 1.15577 & 0.00013 & -0.0158 & 0.0067 \\
\hline $\mathrm{S}_{1}$ & 0.999852 & 1.000148 & 2.9377 & 1.54059 & 0.01517 & 16.8178 & 0.5870 \\
\hline $\mathrm{K}_{1}$ & 1.001824 & 1.003652 & 375.4852 & 1.14166 & 0.00005 & 0.0636 & 0.0022 \\
\hline$\Psi_{1}$ & 1.005328 & 1.005624 & 2.9377 & 1.25028 & 0.00551 & -0.2962 & 0.2522 \\
\hline$\Phi_{1}$ & 1.007594 & 1.013690 & 5.3469 & 1.17338 & 0.00298 & -0.2599 & 0.1457 \\
\hline$\theta_{1}$ & 1.028549 & 1.034468 & 4.0151 & 1.16109 & 0.00379 & -0.1476 & 0.1871 \\
\hline $\mathrm{J}_{1}$ & 1.036291 & 1.044801 & 20.9966 & 1.16283 & 0.00074 & 0.0321 & 0.0364 \\
\hline $\mathrm{SO}_{1}$ & 1.064840 & 1.071084 & 3.4829 & 1.17773 & 0.00428 & -0.3792 & 0.2085 \\
\hline $\mathrm{OO}_{1}$ & 1.072582 & 1.080945 & 11.4890 & 1.16083 & 0.00105 & 0.0193 & 0.0520 \\
\hline$v_{1}$ & 1.099160 & 1.216398 & 2.1997 & 1.16057 & 0.00522 & -0.0122 & 0.2576 \\
\hline$\varepsilon_{2}$ & 1.719380 & 1.837970 & 4.1907 & 1.17978 & 0.00301 & -0.4181 & 0.1461 \\
\hline $2 \mathrm{~N}_{2}$ & 1.853919 & 1.862429 & 14.3723 & 1.17775 & 0.00097 & -0.6015 & 0.0474 \\
\hline$\mu_{2}$ & 1.863633 & 1.872143 & 17.3450 & 1.17678 & 0.00082 & -0.5095 & 0.0399 \\
\hline $\mathrm{N}_{2}$ & 1.888386 & 1.896749 & 108.6131 & 1.17147 & 0.00013 & -0.5821 & 0.0064 \\
\hline$v_{2}$ & 1.897953 & 1.906463 & 20.6300 & 1.16944 & 0.00070 & -0.5976 & 0.0344 \\
\hline $\mathrm{M}_{2}$ & 1.923765 & 1.942754 & 567.2884 & 1.16940 & 0.00003 & -0.4630 & 0.0012 \\
\hline$\lambda_{2}$ & 1.958232 & 1.963709 & 4.1832 & 1.16875 & 0.00341 & -0.4098 & 0.1672 \\
\hline $\mathrm{L}_{2}$ & 1.965826 & 1.976927 & 16.0345 & 1.16998 & 0.00108 & -0.2808 & 0.0530 \\
\hline $\mathrm{T}_{2}$ & 1.991786 & 1.998288 & 15.4312 & 1.17176 & 0.00091 & -0.8329 & 0.0448 \\
\hline $\mathrm{S}_{2}$ & 1.999705 & 2.000767 & 263.9324 & 1.16374 & 0.00006 & -0.6606 & 0.0044 \\
\hline $\mathrm{K}_{2}$ & 2.002590 & 2.013690 & 71.7503 & 1.16479 & 0.00019 & -0.3638 & 0.0092 \\
\hline$\eta_{2}$ & 2.031287 & 2.047391 & 4.0117 & 1.16455 & 0.00306 & 0.0773 & 0.1505 \\
\hline $2 \mathrm{~K}_{2}$ & 2.067578 & 2.182844 & 1.0507 & 1.15762 & 0.00794 & -0.2516 & 0.3928 \\
\hline $\mathrm{MN}_{3}$ & 2.753243 & 2.869714 & 2.6583 & 1.07998 & 0.00271 & 0.0089 & 0.1440 \\
\hline $\mathrm{M}_{3}$ & 2.892639 & 3.081255 & 9.6883 & 1.07891 & 0.00077 & 0.0069 & 0.0410 \\
\hline $\mathrm{M}_{4}$ & 3.791963 & 3.937898 & 0.1533 & 0.96109 & 0.02949 & -0.6953 & 1.7579 \\
\hline
\end{tabular}


Table 2. OTL effects on the tidal gravity observations at the Lhasa station.

\begin{tabular}{|c|c|c|c|c|c|c|c|c|}
\hline \multirow{2}{*}{ waves } & \multicolumn{2}{|c|}{ Observed Residual $B$} & \multicolumn{2}{|c|}{ OTL Vectors $L$} & \multicolumn{2}{|c|}{ Final Residual $X$} & \multicolumn{2}{|c|}{ Amplitude Factors $\delta$} \\
\hline & $B\left(\mathrm{~nm} \mathrm{~s}^{-2}\right)$ & $\beta /\left(^{\circ}\right)$ & $L\left(\mathrm{~nm} \mathrm{~s}^{-2}\right)$ & $\lambda /\left(^{\circ}\right)$ & $X\left(\mathrm{~nm} \mathrm{~s}^{-2}\right)$ & $\chi /\left(^{\circ}\right)$ & Observed & DDW99 \\
\hline $\mathrm{Q}_{1}$ & 0.9096 & 16.97 & 0.5290 & 43.42 & 0.4955 & -11.42 & 1.16375 & 1.1558 \\
\hline $\mathrm{O}_{1}$ & 3.5682 & -1.51 & 1.1180 & 13.45 & 2.5047 & -8.13 & 1.16353 & 1.1556 \\
\hline $\mathrm{P}_{1}$ & 0.8221 & -2.76 & 0.5270 & 150.22 & 1.3136 & -13.26 & 1.15945 & 1.1501 \\
\hline $\mathrm{K}_{1}$ & 2.5675 & 10.68 & 1.5480 & 143.76 & 3.7970 & -6.64 & 1.14499 & 1.1346 \\
\hline $\mathrm{N}_{2}$ & 1.6621 & -51.05 & 1.1340 & -65.52 & 0.6312 & -24.38 & 1.16709 & 1.1594 \\
\hline $\mathrm{M}_{2}$ & 6.8693 & -51.30 & 4.2050 & -85.98 & 4.1671 & -16.25 & 1.16884 & 1.1594 \\
\hline $\mathrm{S}_{2}$ & 3.5756 & -82.05 & 1.2130 & -119.39 & 2.7128 & -66.32 & 1.16596 & 1.1594 \\
\hline $\mathrm{K}_{2}$ & 0.5720 & -68.08 & 0.3260 & -112.66 & 0.4097 & -34.12 & 1.16652 & 1.1594 \\
\hline
\end{tabular}

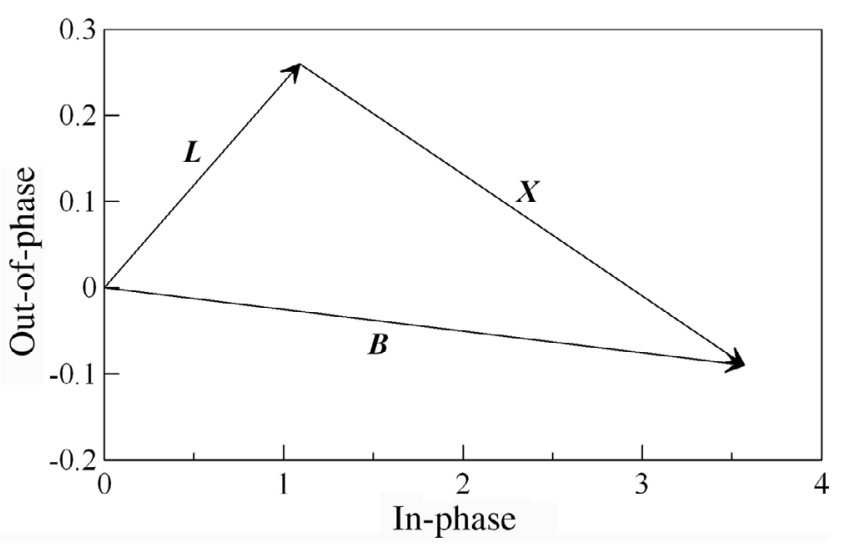

Fig. 5. Loading correction of the oceanic tides for $\mathrm{O}_{1}$ (in $\mathrm{nm} \mathrm{s}^{-2}$ ).

waves decreased slightly except for $\mathrm{P}_{1}$ and $\mathrm{K}_{1}$. The OTL only induced very little perturbation in the gravimetric parameters. The perturbation in the gravimetric parameters excited by the OTL was less than $0.6 \%$ for the tidal waves with amplitude exceeding $20 \mathrm{~nm} \mathrm{~s}^{-2}$. Having removed the oceanic tide load effects, the gravity tides amplitude factors only changed slightly and were slightly closer to the corresponding values in the theoretical and experimental models for the gravity tides (Dehant et al. 1999; Xu et al. 2004a). However, the observed amplitude factors for the di urnal tidal waves were significantly about $0.7 \%$ larger than those from DDW99, while the observed amplitude factors for the semidiurnal tidal waves were about $0.6 \%$ larger than those from DDW99. Compared with the tidal gravity observations from the SG at the inland stations in the other regions (Xu et al. 2004a), the differences between the observed and theoretical amplitude factors are too large, which cannot be explained by the oceanic tide load effects. The other large-scale anomalies in structure and perturbations may be responsible for the differences. In the Tibetan Plateau area, the largest local perturbation is due to variations in the glaciers covering the plateau. However, glacier ablation and its associated rebound are slow processes and hardly affect the tidal deformation of the Earth. As a result, it is acceptable that the relatively large differences between the gravimetric amplitude factors observed with SG-C057 at the Lhasa station and those expected theoretically might be due to the combined contribution of the active tectonic movement of the Tibetan Plateau and its surrounding areas and the regional extremely thick crust. Of course, a more certain conclusion cannot be drawn until SG data are accumulated for a longer period and further associated theoretical studies are carried out.

\section{NON-TIDAL GRAVITY CHANGES AND THE RELATED DYNAMICAL IMPLICATION}

The nontidal gravity changes, i.e., the gravity residuals, were deduced by subtracting the tidal gravity signatures from the original gravity variations and were depicted in Fig. 4b. It is found that there were abundant signatures of high and moderate frequencies in the non-tidal gravity variations in addition to secular tendency and long-period changes which should be related to the instrument drift, the local vertical crust movements, variations in the Earth's rotation and the regional hydrological variations.

The barometric pressure load effects are the largest noise source in the tidal and nontidal gravity observations except for the OTL. The measurement results, presented in Fig. $4 \mathrm{c}$, indicated that there were neither obvious seasonal nor annual variations in the local atmospheric pressure unlike the cases in the other areas with low or moderate latitudes. Instead, the pressure changes mainly concentrated on the short-period perturbations and their magnitude arrived at as large as about $30 \mathrm{hPa}$. In the period from June to September the predominant components of the local barometric pressure variations are high-frequency vibrations with relatively smaller magnitudes, while the frequencies became 
lower and the magnitudes became larger in the remaining periods. The atmospheric gravity admittance was estimated as $-3.631 \pm 0.007 \mathrm{~nm} \mathrm{~s}^{-2} \mathrm{hPa}^{-1}$ at the Lhasa station and was not significantly different from those either predicted by theoretical simulation or obtained with the SGs at the stations in other areas (Sun and Lou 1998; Sun et al. 2001; Xu et al. 2004a, 2008, 2012). In order to intuitively show the local barometric pressure load effects upon the gravity measurement, Fig. 4 shows the nontidal gravity variations measured with the SG (Fig. 4b) and those after removing the atmospheric gravity signatures (Fig. 4d) at the Lhasa station. It was found that almost all obvious gravity disturbances were related to the local atmospheric pressure load effects. Compared with the power spectral density of the gravity residuals before removing the atmospheric effects, it was found that the pressure considerably influenced the gravity measurements in each frequency band. Nearly all vibrations with periods from $3 \mathrm{~h}$ to several days disappeared and the gravity residuals became much smoother and quieter after effects removal. The harmonic analysis results indicate that while the atmospheric effects had been removed, the standard deviation significantly decreased from 4.160 to $0.498 \mathrm{~nm} \mathrm{~s}^{-2}$, the noise levels decreased from $0.2093,0.0668,0.0375$, and $0.0264 \mathrm{~nm} \mathrm{~s}^{-2}$ to $0.0194,0.0177,0.0095$, and $0.0062 \mathrm{~nm} \mathrm{~s}^{-2}$ in the diurnal, semidiurnal, terdiurnal and quarter-diurnal frequency bands, respectively. The white-noise level also decreased from 0.0717 to $0.0070 \mathrm{~nm} \mathrm{~s}^{-2}$.

Previous studies showed that due to the interaction between the elliptical fluid core and the solid mantle, the core moves with a nearly diurnal free wobble (NDFW) relative to the whole Earth and behaves as a free core nutation (FCN) in inertial space, which leads to resonant enhancement in the diurnal gravity tides and gravimetric amplitude factor observations of the diurnal tidal waves depending on their frequencies. The nearly diurnal resonance is an important characteristic of the tidal gravity observations (Defraigne et al. 1994; Dehant et al. 1999; Xu et al. 2002, 2004a). Using tidal gravity observations with SG-C057 at the Lhasa station, the nearly diurnal resonance of the gravimetric parameters were fitted and shown in Fig. 6, and the FCN period was retrieved as $450.5 \pm 8.6$ sidereal days which is slightly longer than those retrieved by stacking the tidal gravity observations from global SGs (Defraigne et al. 1994; Xu et al. 2002, 2004a). Meanwhile, the retrieved quality factor was negative. The main reason is tiny disturbance in the gravimetric parameters related to the active tectonic movement of Tibetan Plateau and its adjacent areas and the regional extremely thick crust, in addition to uncertainty in oceanic tide models in the Indian Ocean.

The Earth's free oscillations (EFO) can be excited by a great earthquake. The EFO are classified as spheroidal and toroidal oscillations, and the former are associated with cubical dilation and gravity changes which can be detected by the high-precision gravimeters installed on the ground. It was proven that the SG played an important role in structuring the long-period seismogram (Banka and Crossley 1999; Van Camp 1999; Lei et al. 2005; Park et al. 2005). On March 11, 2011, the magnitude 9.0 Tohoku-Oki Earthquake released such large energy that the Pacific tsunami was generated and the EFO were excited. The Lhasa station is located

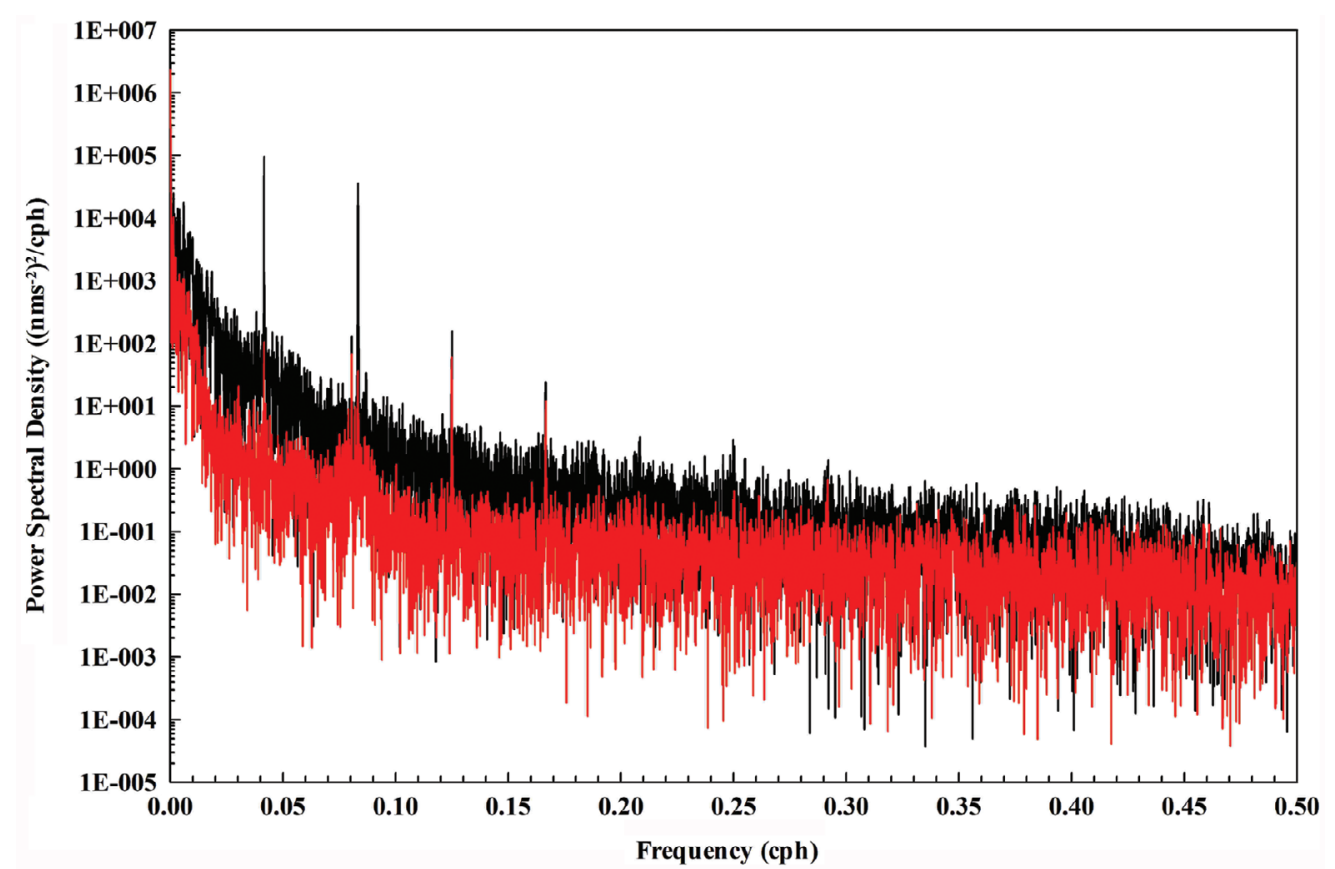

Fig. 6. Power spectral density of gravity residuals from the SG at the Lhasa station before (black) and after (red) removal of barometric pressure effects. 
on the Tibetan Plateau where many small earthquakes near the station were induced by the event due to active tectonic movements and the complicated tectonic environment. However, the SG successfully caught the signatures related to the EFO excited by this event although the mean level of background noise spectrum was a little higher than 1 (nm $\left.\mathrm{s}^{-2}\right)^{2} \mathrm{~Hz}^{-1}$ in frequency less than $0.5 \mathrm{mHz}$. The results indicate that the signal-to-noise ratio (SNR) was still larger than 5.0 for modes $0 \mathrm{~S} 2$ and $0 \mathrm{~S} 3$, and higher than 10 for other EFO modes except 1S2 whose SNR was also beyond 3.0. The spectral peaks nearby $0.945 \mathrm{mHz}$ were generated by $1 \mathrm{~S} 3,2 \mathrm{~S} 2$ and $3 \mathrm{~S} 1$ modes, but they cannot be accurately distinguished at present. This is the first time that the EFO modes were observed at a plateau station. The spectral peaks of the EFO modes with frequencies less than $1.5 \mathrm{mHz}$ were presented in Fig. 7.

\section{CONCLUSION}

Gravimetric parameters were accurately determined using the SG data recorded at the Lhasa station from December 8, 2009 to September 30, 2011. The standard deviation was as little as $0.498 \mathrm{~nm} \mathrm{~s}^{-2}$. The precision was better than $0.002 \%$ for the four main tidal waves and better than $0.02 \%$ for the other tidal waves with ampitudes exceeding $20 \mathrm{~nm} \mathrm{~s}^{-2}$. This implies that the tidal gravity observations made with the SG at the Lhasa station were so accurate that they can act as a regional tidal gravity reference for the gravity measurements in the Tibetan Plateau and its surrounding regions. The OTL vectors were obtained based on the classical theory of the Earth's surface loads and global oceanic tide model Fes04. It was found that the OTL effects on the tidal gravity observations made with the SG at the Lhasa station were very tiny. The OTL resulted only in slight perturbations in the observed gravimetric parameters. After removal of the OTL effects, the difference in the observations and the recent theoretical model was still significantly as large as $0.7 \%$ for the diurnal gravity tides and about $0.6 \%$ for the semidiurnal gravity tides. In other words, the OTL cannot reasonbaly explain so large a difference, instead, the active tectonic movements and extremely thick crust in the areas surrounding the station may be responsible for the differences. For the same reason, the FCN period retrieved from the SG observations obtained at the Lhasa station was slightly longer than the one retrieved by stacking the tidal gravity observations from global SGs.

There were abundant signatures in the non-tidal gravity variations recorded with the SG at the Lhasa station. The numerical results indicate that there were neither obvious seasonal nor annual variations in the local atmospheric pressure. Almost all of the obvious gravity disturbances were related to the local atmospheric pressure load effects. The pressure considerably influenced the gravity measurements in each frequency band. After removing the atmospheric effects all of the high and moderate frequency vibrations disappeared and the gravity residuals became much smoother and quieter. In addition, the Earth's free oscillations excited by the 2011 Tohoku-Oki $\mathrm{M}_{\mathrm{w}}$ 9.0 Earthquake were successfully detected by the SG at the Lhasa station. This is the first time that the EFO modes were observed at a plateau station.

With the SG data accumulation, combining the continuous GPS data and repeated FG5 measurements, it is hopeful that some hotspots in continent dynamics in the Tibentan Plateau will be investigated further.

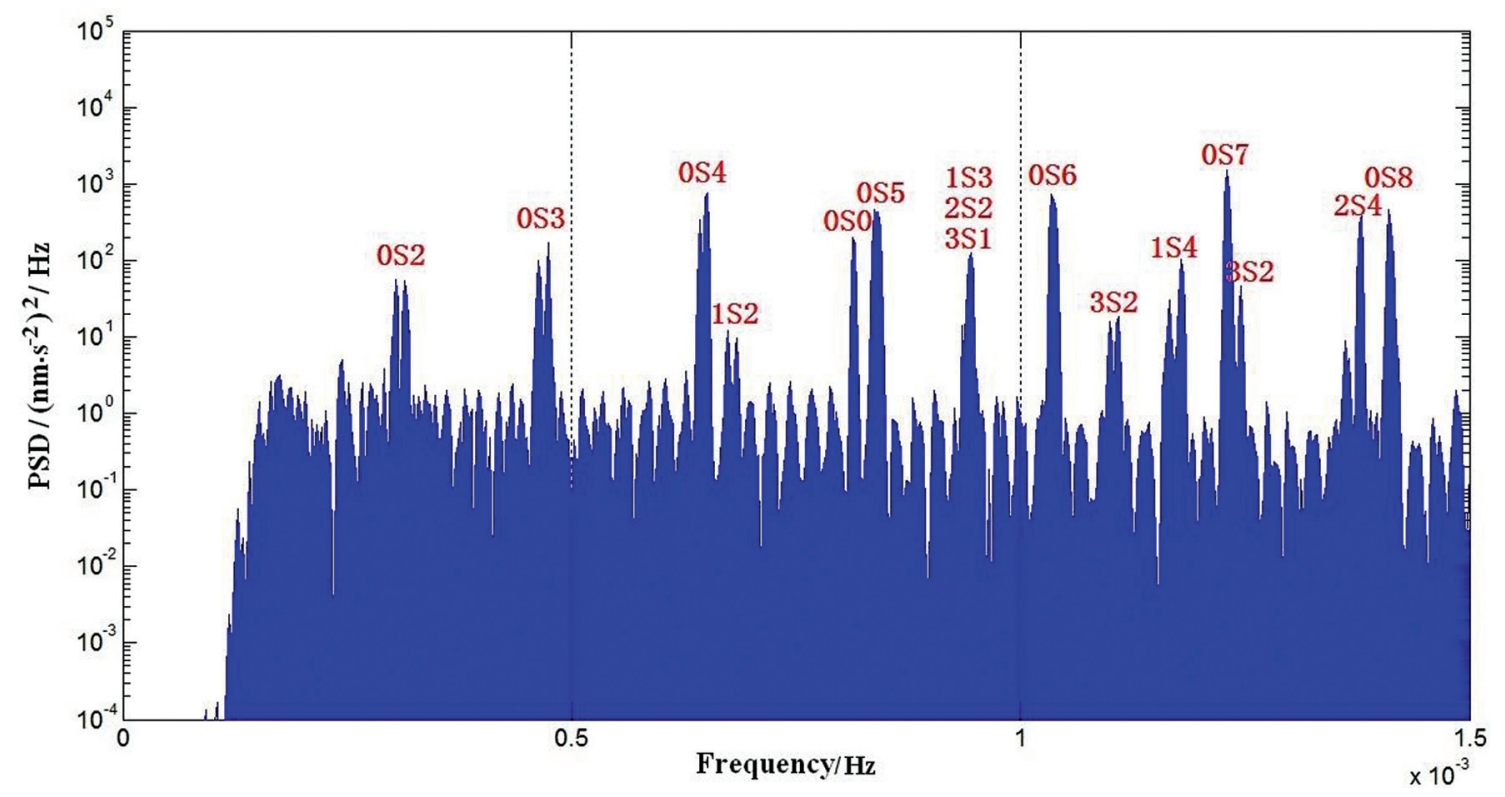

Fig. 7. EFO Spectrum excited by Japan great earthquake at Lhasa station. 
Acknowledgements The authors would like to thank the staff in the Wuhan and Lhasa stations for providing highquality SG data. This work is Supported by National Natural Science Foundation of China (Grant Nos. 40874038, 41074053 and 41021003).

\section{REFERENCES}

Agnew, D. C., 1997: A program for computing ocean-tide loading. J. Geophys. Res., 102, B3, 5109-5110, doi: 10. 1029/96JB03458. [Link]

Banka, D. and D. Crossley, 1999: Noise levels of superconducting gravimeters at seismic frequencies. Geophys. J. Int., 139, 87-97, doi: 10.1046/j.1365-246X.1999.00 913.x. [Link]

Chen, X., H. Sun, H. Xu, J. Xu, X. Hao, and M. Liu, 2013: Determination of the calibration factor of superconducting gravimeter 057 at the Lhasa station: A frequency-domain approach. Terr. Atmos. Ocean. Sci., 24, 629-636, doi: 10.3319/TAO.2012.12.03.02(TibXS). [Link]

Courtier, N., B. Ducarme, J. Goodkind, J. Hinderer, Y. Imanishi, N. Seama, H. Sun, J. Merriam, B. Bengert, and D. E. Smylie, 2000: Global superconducting gravimeter observations and the search for the translational modes of the inner core. Phys. Earth Planet. Inter., 117, 3-20, doi: 10.1016/S0031-9201(99)00083-7. [Link]

Crossley, D., 2004: Preface to the Global Geodynamics Project. J. Geodyn., 38, 225-236, doi: 10.1016/j.jog. 2004.07.002. [Link]

Crossley, D. and J. Hinderer, 2009: A review of the GGP network and scientific challenges. J. Geodyn., 48, 299304, doi: 10.1016/j.jog.2009.09.019. [Link]

Crossley, D., J. Hinderer, G. Casula, O. Francis, H.-T. Hsu, Y. Imanishi, G. Jentzsch, J. Kääriänen, J. Merriam, B. Meurers, J. Neumeyer, B. Richter, K. Shibuya, T. Sato, and T. van Dam, 1999: Network of superconducting gravimeters benefits a number of disciplines. Eos, Trans., AGU, 80, 121-126, doi: 10.1029/99EO00079. [Link]

Crossley, D., J. Hinderer, and J. P. Boy, 2004: Regional gravity variations in Europe from superconducting gravimeters. J. Geodyn., 38, 325-342, doi: 10.1016/j. jog.2004.07.014. [Link]

Defraigne, P., V. Dehant, and J. Hinderer, 1994: Stacking gravity tide measurements and nutation observations in order to determine the complex eigenfrequency of the nearly diurnal free wobble. J. Geophys. Res., 99, B5, 9203-9213, doi: 10.1029/94JB00133. [Link]

Dehant, V., P. Defraigne, and J. M. Wahr, 1999: Tides for a convective Earth. J. Geophys. Res., 104, 1035-1058, doi: 10.1029/1998JB900051. [Link]

Farrell, W. E., 1972: Deformation of the Earth by surface loads. Rev. Geophys., 10, 761-797, doi: 10.1029/RG01 0i003p00761. [Link]

Hartmann, T. and H.-G. Wenzel, 1995: The HW95 tidal potential catalogue. Geophys. Res. Lett., 22, 3553-3556, doi: 10.1029/95GL03324. [Link]

Imanishi, Y., T. Sato, T. Higashi, W. Sun, and S. Okubo, 2004: A network of superconducting gravimeters detects submicrogal coseismic gravity changes. Science, 306, 476-478, doi: 10.1126/science.1101875. [Link]

Lefevre, F., F. H. Lyard, C. Le Provost, and E. J. O. Schrama, 2002: FES99: A global tide finite element solution assimilating tide gauge and altimetric information. J. Atmos. Ocean. Technol., 19, 1345-1356, doi: 10.11 75/1520-0426(2002)019<1345:FAGTFE >2.0.CO;2. [Link]

Lei, X., H. Xu, and H. Sun, 2005: Detection of spheriodal free oscillation excited by Peru 8.2 Ms earthquake with five international superconducting gravimeter data. Sci. China, Ser. D, 48, 123-133.

Loyer, S., J. Hinderer, and J.-P. Boy, 1999: Determination of the gravimetric factor at the Chandler period from Earth orientation data and superconducting gravimetry observations. Geophys. J. Int., 136, 1-7, doi: 10.1046/ j.1365-246X.1999.00646.x. [Link]

Ma, Z., X. Chen, S. Ye, X. Lai, Z. Wei, J. Chen, J. Ning, H. $\mathrm{Xu}$, and G. Ding, 2001. Contemporary crustal movement of continental China obtained by Global Positioning System (GPS) measurements. Chin. Sci. Bull., 46, 1552-1554, doi: 10.1007/BF02900579. [Link]

Park, J., T.-R. A. Song, J. Tromp, E. Okal, S. Stein, G. Roult, E. Clevede, G. Laske, H. Kanamori, P. Davis, J. Berger, C. Braitenberg, M. Van Camp, X. Lei, H. Sun, H. Xu, and S. Rosat, 2005: Earth's Free oscillations excited by the 26 December 2004 Sumatra-Andaman earthquake. Science, 308, 1139-1144, doi: 10.1126/science.1112305. [Link]

Richter, B., S. Zerbini, F. Matonti, and D. Simon, 2004: Long-term crustal deformation monitored by gravity and space techniques at Medicina, Italy and Wettzell, Germany. J. Geodyn., 38, 281-292, doi: 10.1016/j.jog. 2004.07.013. [Link]

Rosat, S., J. Hinderer, D. Crossley, and L. Rivera 2003: The search for the Slichter mode: Comparison of noise levels of superconducting gravimeters and investigation of a stacking method. Phys. Earth Planet. Inter., 140, 183-202, doi: 10.1016/j.pepi.2003.07.010. [Link]

Smylie, D. E., 1992: The inner core translational triplet and the density near Earth's center. Science, 255, 16781682, doi: 10.1126/science.255.5052.1678. [Link]

Sun, H. and S. Luo, 1998: Theoretical computation and detection of the atmospheric gravity signals. Chin. J. Geophys., 41, 634-641. (in Chinese)

Sun, H., S. Takemoto, H. T. Hsu, T. Higashi, and A. Mukai, 2001: Precise tidal gravity recorded with superconducting gravimeters at stations Wuhan (China) and 
Kyoto (Japan). J. Geodesy, 74, 720-729, doi: 10.1007/ s001900000139. [Link]

Sun, W., Q. Wang, H. Li, Y. Wang, S. Okubo, D. Shao, D. Liu, and G. Fu, 2009: Gravity and GPS measurements reveal mass loss beneath the Tibetan Plateau: Geodetic evidence of increasing crustal thickness. Geophys. Res. Lett., 36, L02303, doi: 10.1029/2008GL036512. [Link]

Van Camp, M., 1999: Measuring seismic normal modes with the GWR C021 superconducting gravimeter. Phys. Earth Planet. Inter., 116, 81-92, doi: 10.1016/ S0031-9201(99)00120-X. [Link]

Vauterin, P., 1998: Tsoft: Graphical and interactive software for the analysis of Earth tide data. In: Ducarme, B. and P. Paquet (Ed.), Proceeding of $13^{\text {th }}$ International Symposium on Earth Tides, Brussels, 481-486.

Wang, Q., P. Z. Zhang, J. T. Freymueller, R. Bilham, K. M. Larson, X. Lai, X. You, Z. Niu, J. Wu, Y. Li, J. Liu, Z. Yang, and Q. Chen, 2001: Present-day crustal deformation in China constrained by global positioning system measurements. Sciences, 294, 574-577, doi: 10.1126/science.1063647. [Link]

Wang, Y., W. Zhang, J. Zhan, and X Hao, 2004: Gravity change detected by repeated absolute gravity measurements in the western Yuannan and Lhasa, China and its implication. Chin.J. Geophys., 47, 95-100. (in Chinese)

Wenzel, H.-G., 1996: The nanogal software: Earth tide data processing package ETERNA 3.30. Bull. Inf. Marees Terr., 124, 9425-9439.

Xu, H., H. Sun, J. Xu, and G. Tao, 2000: International tidal gravity reference values at Wuhan station. Sci. China, Ser. $D, \mathbf{4 3}, 77-83$.

Xu, H., 2001: Geodetic studies on Tibetan Plateau. Hubei Sci. Technol. Press. Wuhan, 3-67. (in Chinese)

Xu, J., H. Sun, and S. Luo, 2002: Study of the Earth's free core nutation by tidal gravity data recorded with international superconducting gravimeters. Sci. China, Ser. $D, 45,337-347$.

Xu, J., H. Sun, and B. Ducarme, 2004a: A global experimental model for gravity tides of the Earth. J. Geodyn., 38, 293-306, doi: 10.1016/j.jog.2004.07.003. [Link]

Xu, J., H. Sun, and X. Yang, 2004b: A study of gravity variations caused by polar motion using superconducting gravimeter data from the GGP network. J. Geodesy, 78, 201-209, doi: 10.1007/s00190-004-0386-1. [Link]

Xu, J., J. Zhou, S. Luo, and H. Sun, 2008: Study on characteristics of long-term gravity changes at Wuhan station. Chin. Sci. Bull., 53, 2033-2040, doi: 10.1007/s11434008-0074-2. [Link]

Xu, J., H. Sun, and J. Zhou, 2010: Experimental detection of the inner core translational triplet. Chin. Sci. Bull., 55, 276-283, doi: 10.1007/s11434-009-0479-6. [Link]

Xu, J., X. Chen, J. Zhou, and H. Sun, 2012: Characteristics of tidal gravity changes in Lhasa, Tibet, China. Chin. Sci. Bull., 57, 2586-2594, doi: 10.1007/s11434-012-5 130-2. [Link]

Zhang, P., Q. Wang, and Z. Ma, 2002: GPS velocity field and active crustal blocks of contemporary tectonic deformation in continental China. Earth Sci. Front., 9, 430-441. (in Chinese) 